\title{
Originals
}

\section{Glycaemia, arterial pressure and micro-albuminuria in Type 1 (insulin-dependent) diabetes mellitus}

\author{
M. Wiseman, G. Viberti, D. Mackintosh, R. J.Jarrett and H. Keen \\ Unit for Metabolic Medicine and Department of Community Medicine, Guy’s Hospital Medical School, London, UK
}

\begin{abstract}
Summary. Plasma glucose control and arterial pressure were assessed in 28 Type 1 (insulin-dependent) diabetic patients with different degrees of micro-albuminuria. They were divided into two groups according to their urinary albumin excretion rate: a low micro-albuminuria group $(n=16)$ with albumin excretion ranging between 12.1 and $28.9 \mu \mathrm{g} / \mathrm{min}$ and a high micro-albuminuria group $(n=12)$ with albumin excretion between 32.4 and $91.3 \mu \mathrm{g} / \mathrm{min}$. The groups were matched for age, sex and duration of diabetes with the same number of normo-albuminuric $(2.0-10.4 \mu \mathrm{g} / \mathrm{min})$ diabetic control subjects. Both the low and high micro-albuminuria groups had significantly higher glycosylated haemoglobin levels and mean plasma glucose concentrations during a 24-h profile than their respective normo-albuminuric control subjects. A correlation between glycosylated haemoglobin level and urinary albumin excretion rate was found in the whole study group $(r=0.48 ; p<0.001)$. Arterial pressure (both systolic and diastolic) was significantly higher in the high micro-albuminuria group than in either the control group or the low micro-
\end{abstract}

albuminuria group. A significant correlation was found between arterial pressure and albumin excretion rate in the whole study population $(r=0.49 ; p<0.001)$ as well as in the pooled micro-albuminuria groups $(r=0.43 ; p<0.05)$. Multiple regression analysis showed that glycosylated haemoglobin and arterial pressure levels were independently correlated with albumin excretion rates. Diabetic patients with micro-albuminuria of any degree have worse glycaemic control than normo-albuminuric patients. Higher levels of arterial pressure, though often sub-hypertensive, are associated with levels of micro-albuminuria predictive of later development of clinical proteinuria. Thus high plasma glucose and high arterial pressure, or both, characterise those diabetic patients at increased risk of nephropathy. These indices of risk are potentially reversible.

Key words: Plasma glucose, urinary albumin excretion, glycosylated haemoglobin, blood pressure, hypertension, Type 1 diabetes
Prospective studies $[1,2]$ have shown that certain rates of urinary albumin excretion above the normal range, but falling short of clinical proteinuria (i. e. micro-albuminuria in excess of $30 \mu \mathrm{g} / \mathrm{min}$ ), in Type 1 (insulin-dependent) diabetic patients are highly predictive of later development of Albustix-positive proteinuria, itself a regular harbinger of renal failure. The factors responsible for this degree of micro-albuminuria are, however, still unclear and the studies reported so far were not specifically designed to investigate them [1, 2]. A better knowledge of the associations of micro-albuminuria is important, for appropriate therapy might reduce the risk of ultimate renal failure.

In the present study, we relate varying degrees of urinary albumin hyperexcretion in a selected group of Type 1 diabetic patients to prevailing plasma glucose and arterial pressure levels and compare them with a matched group of diabetic control subjects with normal urinary albumin excretion rate.

\section{Subjects and methods}

\begin{abstract}
Subjects
During a screening programme of patients attending the diabetic clinic at Guy's Hospital, the 24-h urinary albumin excretion rate was measured. All patients were deemed clinically to be insulin-dependent and had a typical onset of diabetes mellitus at least 2 years previously, negative Albustix (Ames) tests for urinary protein, serum creatinine within the normal range $(30-110 \mu \mathrm{mol} / \mathrm{l})$, were without signs of cardiac failure and had no history of renal or urinary tract disease. All patients were within $10 \%$ of ideal body weight and gave informed consent to the study which was approved by the Hospital Ethical Committee.

Twenty-eight patients with micro-albuminuria (the upper limit of the normal range calculated as mean $+2 \mathrm{SD}$ in our laboratory is $12 \mu \mathrm{g} / \mathrm{min})[3,4]$ were identified. They were subsequently divided into two groups: 16 with urinary albumin excretion $<30 \mu \mathrm{g} / \mathrm{min}$ (range: $12.1-28.9 \mu \mathrm{g} / \mathrm{min}$ ), a level poorly predictive of later clinical proteinuria, and 12 with albumin excretion $>30 \mu \mathrm{g} / \mathrm{min}$ (range: $32.4-91.3$ $\mu \mathrm{g} / \mathrm{min}$ ), a level highly predictive of later Albustix-positive proteinuria [1]. These two groups, termed 'low' and 'high' micro-albuminuria respectively, were matched for age, duration of diabetes and sex (in
\end{abstract}


Table 1. Clinical features of micro-albuminuric patients and their normo-albuminuric control subjects

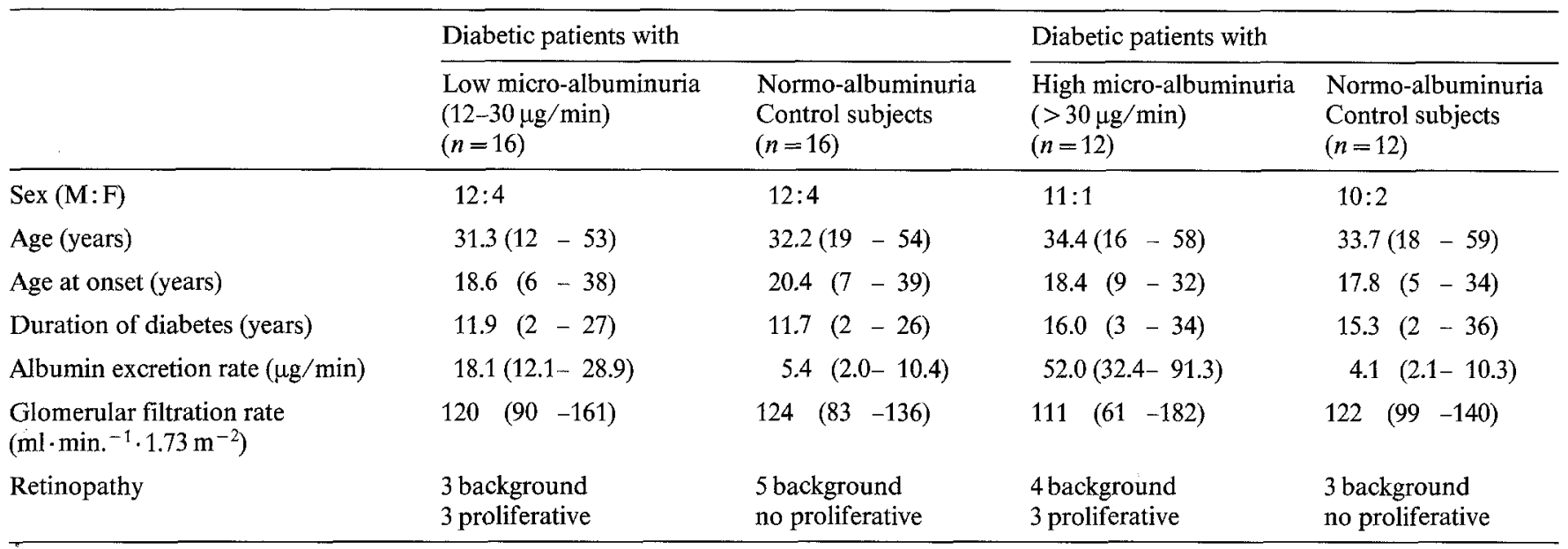

Results are expressed as mean with the range in parentheses.

No significant differences between either diabetic group and its control group were found in age, sex, duration of diabetes or glomerular filtration rate

Table 2. $\mathrm{HbA}_{1 \mathrm{c}}$ levels in micro-albuminuric diabetic patients and matched normo-albuminuric diabetic control subjects

\begin{tabular}{llllcc} 
& $\begin{array}{l}\text { Low micro-albuminuria } \\
\text { group }(n=16)\end{array}$ & $\begin{array}{l}\text { Control group } \\
(n=16)\end{array}$ & $p$ & $\begin{array}{l}\text { High micro-albuminuria } \\
\text { group }(n=12)\end{array}$ & $\begin{array}{l}\text { Control group } \\
(n=12)\end{array}$ \\
\hline $\mathrm{HbA}_{1 \mathrm{c}}$ & $12.1 \pm 2.1$ & $10.5 \pm 1.8$ & $<0.05$ & $12.2 \pm 1.4$ & $9.8 \pm 1.2$ \\
$(\%)$ & $(8.3-16.9)$ & $(7.4-13.2)$ & & $(10.3-14.1)$ & $(7.6-11.4)$ \\
\hline
\end{tabular}

Results are expressed as mean $\pm \mathrm{SD}$ with range in parentheses

order of importance) with the same number of insulin-dependent diabetic patients whose albumin excretion rate during the screening procedure had been in the normal range (between 2 and 10.4 $\mu \mathrm{g} / \mathrm{min}$ ) and who also had normal serum creatinine concentrations and no history of renal dysfunction. We aimed for matching for age within 5 years and duration of diabetes within 3 years. However, in one case this was not possible (Table 1 ).

Glomerular filtration rate (GFR) was measured in nine of the high micro-albuminuria group and in 12 of the low micro-albuminuria group, and their respective controls (Table 1). Table 1 gives the clinical features of the low and high micro-albuminuria patients and their respective control groups. All patients had negative urine cultures.

\section{Methods}

During the 24-h stay in a metabolic ward for screening, a plasma glucose profile was constructed and $24-\mathrm{h}$ urine output collected. No attempt was made to alter diabetic control in these patients who were thus studied under conditions of 'ordinary' glycaemic control.Blood pressure was measured four times (twice supine and twice standing) by a trained observer in the right arm with a conventional mercury sphygmomanometer during the stay in the metabolic ward; Korotkoff phase IV was taken as the diastolic pressure. The mean of all four measurements was used for calculations. Samples for glycosylated haemoglobin $\left(\mathrm{HbA}_{\mathrm{Ic}}\right)$ were taken in the fasting state and measured by electrofocussing [5]. Plasma glucose was measured by the glucose oxidase method (Analox GM6, Analox Instruments, London, UK) and urinary concentration of albumin [6] and $\beta_{2}$-microglobulin by radioimmunoassay (Phadebas- $\beta 2$-microtest, Pharmacia, Uppsala, Sweden). The inter-assay coefficient of variation for the albumin method is $13.6 \%$ and the intra-assay variation is $5.1 \%$. GFR was measured as ${ }^{51} \mathrm{Cr}$ EDTA clearance [7]. Excretion rates were calculated from concentration and 24-h urine volume. Retinopathy was assessed by direct ophthalmoscopy after pupillary dilation. Measurements of blood pressure, plasma glucose, $\mathrm{HbA}_{1 \mathrm{c}}$ and GFR were made in ignorance of the albumin excretion rate of the patients.

\section{Statistical analysis}

Statistical evaluation was performed using Student's t-test for unpaired samples as well as linear and multiple regression analysis. Albumin excretion rates were transformed to $\log _{10}$ values for calculations because of their positively skewed distribution.

\section{Results}

Both the low and high micro-albuminuria groups had significantly higher levels of $\mathrm{HbA}_{1 \mathrm{c}}$ than their respective diabetic control groups (Table 2). No significant difference was found between the low and high micro-albuminuria groups. There was a significant correlation between albumin excretion rate and $\mathrm{HbA}_{1 \mathrm{c}}$ levels in all diabetic patients combined $(r=0.48, p<0.001)$, confirming previous findings [3]. That glycaemic control was poorer in the micro-albuminuria patients was also indicated by their 24-h glycaemic profiles (Fig. 1). Mean plasma glucose was consistently higher throughout the day in the micro-albuminuric patients, the difference reaching statistical significance at $16.00,18.00$ and $24.00 \mathrm{~h}(p<0.05)$. Plasma glucose profiles in the low and high micro-albuminuria groups were similar and statistically indistinguishable. There was no significant 


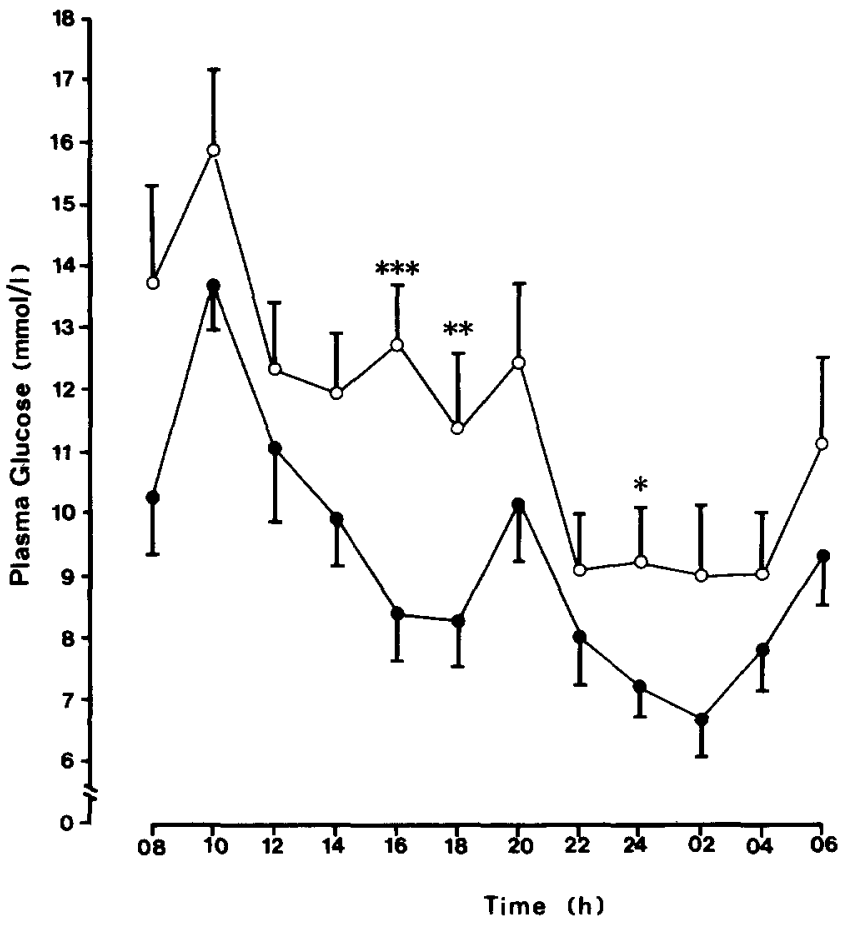

Fig. 1. Mean \pm SEM plasma glucose levels in 28 micro-albuminuric diabetic patients $(\mathrm{O}-\mathrm{O})$ and 28 normo-albuminuric diabetic control subjects $(-$ ) during a $24-\mathrm{h}$ profile. $* p<0.05 * * p<0.02$ $* * * p<0.001$

linear or non-linear correlation between plasma glucose and albumin excretion rate.

The mean values for systolic and diastolic blood pressures in the low micro-albuminuria group did not differ from those of their control group, but corresponding mean pressure values in the high micro-albuminuria group were significantly higher than those of their control group and of the low micro-albuminuria group (Table 3). The mean blood pressure (calculated as diastolic blood pressure + one-third of pulse pressure) was also significantly higher in the group with high micro-albuminuria (Fig. 2). A significant correlation was found between mean blood pressure values and albumin excretion rates in the whole study population $(r=0.49 ; p<0.001)$ as well as in the pooled micro-albuminuria groups alone $(r=0.43 ; p<0.05)$. Multiple regression analysis on the whole study population

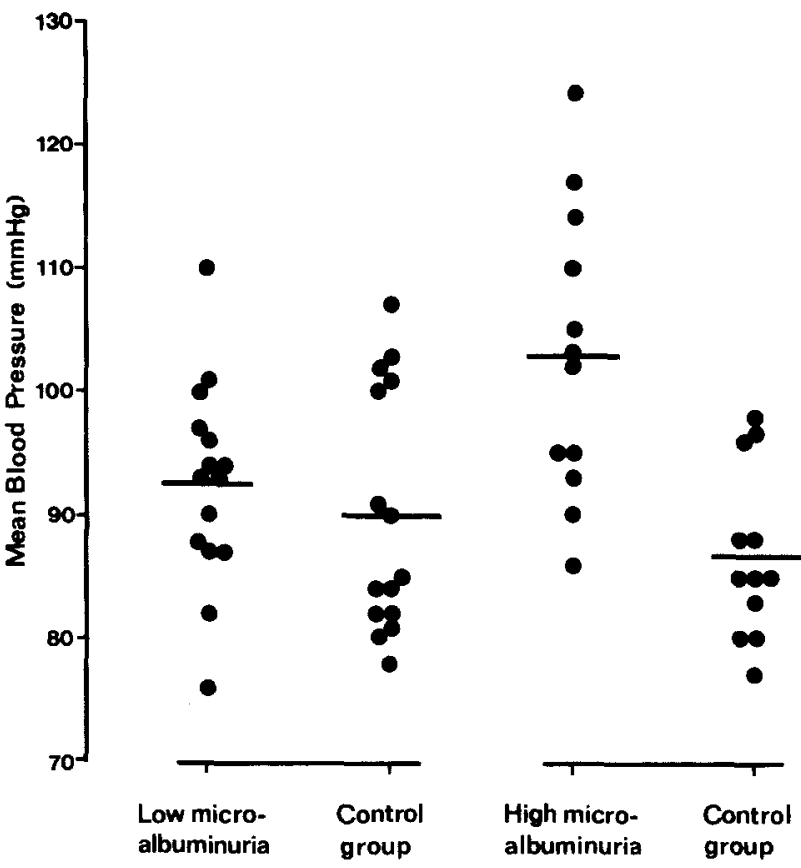

Fig. 2. Mean blood pressures in 16 Type 1 diabetic patients with low micro-albuminuria (albumin excretion rate between 12 and $30 \mu \mathrm{g} /$ $\min$ ) and 12 with high micro-albuminuria (albumin excretion rate $>$ $30 \mu \mathrm{g} / \mathrm{min}$ ) and their respective normo-albuminuric control groups. Horizontal bars indicate mean values for each group. Mean blood pressure was significantly higher in the group with high micro-albuminuria $(102.8 \pm 11.7 \mathrm{mmHg})$ than in the control group $(86.8 \pm$ $6.9 \mathrm{mmHg} ; p<0.001)$ and the group with low micro-albuminuria $(92.5 \pm 8.2 \mathrm{mmHg} ; p<0.02)$. Mean blood pressure did not differ significantly between the low micro-albuminuria group and its control group $(90.0 \pm 9.9 \mathrm{mmHg})$

showed that mean blood pressure and $\mathrm{HbA}_{1 \mathrm{c}}$ related independently to albumin excretion rates $(\mathrm{t}$ value $=3.12$, $p<0.005$ and $\mathrm{t}$ value $=2.86, p<0.01$ respectively, when both variables are included in the regression model), as suggested by lack of significant correlation of their cross product term with albumin excretion $(\mathrm{t}$ value $=-1.30$; NS). All patients had normal urinary excretion rates of $\beta_{2}$-microglobulin. Mean GFR did not differ significantly between the groups (Table 1). No significant correlation was found between $\mathrm{HbA}_{1 \mathrm{c}}$ and mean blood pressure levels nor between albumin excretion rate and age of onset, duration of diabetes or GFR.

Table 3. Systolic and diastolic blood pressures in diabetic patients with micro-albuminuria and matched normo-albuminuric diabetic control subjects

\begin{tabular}{|c|c|c|c|c|c|c|}
\hline Blood pressure $(\mathrm{mmHg})$ & $\begin{array}{l}\text { Low micro-albuminuria } \\
\text { group }(n=16)\end{array}$ & $\begin{array}{l}\text { Control group } \\
(n=16)\end{array}$ & $p$ & $\begin{array}{l}\text { High micro-albuminuria } \\
\text { group }(n=12)\end{array}$ & $\begin{array}{l}\text { Control group } \\
(n=12)\end{array}$ & $p$ \\
\hline Systolic & $\begin{array}{l}119.0 \pm 9.8 \\
(104-135)\end{array}$ & $\begin{array}{l}117.1 \pm 9.5 \\
(103-130)\end{array}$ & NS & $\begin{array}{c}135.5 \pm 18.1 \\
(114-172)\end{array}$ & $\begin{array}{l}117.9 \pm 7.8 \\
(109-132)\end{array}$ & $<0.005$ \\
\hline Diastolic & $\begin{array}{l}78.9 \pm 8.5 \\
(61-97)\end{array}$ & $\begin{array}{l}76.4 \pm 10.7 \\
(66-96)\end{array}$ & NS & $\begin{array}{l}86.5 \pm 8.9 \\
(72-100)\end{array}$ & $\begin{array}{r}71.8 \pm \\
(62-86)\end{array}$ & $<0.001$ \\
\hline
\end{tabular}

Results are expressed as mean \pm SD with range in parentheses.

The high micro-albuminuria group had significantly higher systolic $(p<0.01)$ and diastolic $(p<0.05)$ blood pressures than the low micro-albuminuria group 


\section{Discussion}

Several previous reports have suggested a relationship between glycaemia and urinary albumin excretion both in man and animals [8-14]. Our findings demonstrate that on a sample day (plasma glucose profile) and over the preceding few weeks $\left(\mathrm{HbA}_{1 \mathrm{c}}\right)$ diabetic patients with micro-albuminuria have worse glycaemic control than those with normal albumin excretion rates. Although from a cross-sectional observation it is not possible to exclude the possibility that micro-albuminuric diabetic patients are independently susceptible to more severe diabetes and microvascular disease, there is growing experimental and epidemiological evidence causally relating microangiopathy to glycaemic control $[15,16]$.

The correlation between $\mathrm{HbA}_{1 \mathrm{c}}$ and albumin excretion rate suggests that chronic hyperglycaemia, with consequent glycosylation of plasma proteins [17] and of structural proteins in the glomerular membrane [18], may play a role in the increased transglomerular flux of albumin, in addition to an acute effect of plasma glucose levels upon glomerular haemodynamics $[13,19]$.

However, in our study there was no significant difference in glycaemic control between high and low risk micro-albuminuric groups, which suggests that factors other than poor glycaemic control are required in some diabetic patients to advance them into the 'high risk' micro-albuminuric group. There was a difference in average blood pressure between high and low risk groups which could be interpreted in two ways. Albumin excretion $>30 \mu \mathrm{g} / \mathrm{min}$ might indicate renal dysfunction sufficient to raise the blood pressure. Alternatively, a raised blood pressure, albeit of modest degree and still within the 'normal' range, may increase albuminuria. These hypotheses are not mutually exclusive. An association between blood pressure and albumin excretion rate has been previously reported in both diabetic and non-diabetic subjects $[8,20,21]$ and experimental studies have demonstrated a synergy between high blood pressure and hyperglycaemia upon renal disease $[22,23]$.

In this and previous studies [1,2], the average duration of diabetes was longer, though not significantly so, in patients with micro-albuminuria in excess of $30 \mu \mathrm{g}$ / min than in those with lesser degrees of albumin excretion, suggesting that the former patients may have been further along the road to nephropathy. The selection procedure of our study may have obscured the effect of duration by excluding diabetic patients with Albustixpositive proteinuria. However the close matching between the high micro-albuminuria group and the normo-albuminuric control group excludes the possibility that, in this particular group of patients, duration of diabetes is a primary determinant of high micro-albuminuria. The apparent discrepancy with previous studies [1, 2] that reported no difference in the arterial pressure between patients with urinary albumin excretion above or below $30 \mu \mathrm{g} / \mathrm{min}$ can probably be ascribed to study design. In previous investigations the blood pressure was measured by different observers in the out-patient clinic, in a non-standard manner. By contrast the present study was specifically designed to investigate this variable with multiple measurements of blood pressure by a single observer. Reduction of blood pressure in essential hypertension and plasma glucose levels in diabetes diminishes albumin excretion [9, 25]. As the relationship between arterial pressure and risk of vascular disease observed in population studies is a continuum [26], the question arises of what levels of arterial pressure merit treatment in diabetes. It may be that in high-risk diabetic patients, i.e. with micro-albuminuria $>30 \mu \mathrm{g} / \mathrm{min}$, hypotensive therapy would be beneficial at only moderately elevated levels of blood pressure. Further studies are planned to investigate this hypothesis.

Acknowledgements. We are grateful to Miss A.Collins and $\mathrm{Mr}$. A. James for skilful technical assistance. This work was supported by the Wellcome Trust and the National Medical Research Fund.

\section{References}

1. Viberti GC, Hill RD, Jarrett RJ, Argyropoulos A, Mahmud U, Keen H (1982) Micro-albuminuria as a predictor of clinical nephropathy in insulin-dependent diabetes mellitus. Lancet 1: $1430-1432$

2. Parving H-H, Oxenbøll B, Svendsen PAa, Christiansen JS, Andersen AR (1982) Early detection of patients at risk of developing diabetic nephropathy. A longitudinal study of urinary albumin excretion. Acta Endocrinol 100; 550-555

3. Viberti GC, Mackintosh D, Bilous RW, Pickup JC, Keen H (1982) Proteinuria in diabetes mellitus: Role of spontaneous and experimental variation of glycaemia. Kidney Int 21: 714-720

4. Viberti GC, Mackintosh D, Keen H (1983) Determinants of the penetration of proteins through the glomerular barrier in insulindependent diabetes mellitus. Diabetes 32 (Suppl 2), 92-95

5. Jeppson IO, Franzen B, Nilsson KO (1978) Determination of the glycosylated haemoglobin fraction $\mathrm{HbA}_{\mathrm{cc}}$ in diabetes mellitus by thin-layer electrofocussing. Science Tools 25:69-72

6. Keen H, Chlouverakis C (1963) An immunoassay method for urinary albumin at low concentrations. Lancet 2: 913-916

7. Chantler C, Garnett ES, Parsons V, Veall N (1969) Glomerular filtration rate measurement in man by the single injection method using ${ }^{51}$ Cr EDTA. Clin Sci 37: 169-180

8. Keen H, Chlouverakis C, Fuller J, Jarrett RJ (1969) The concomitants of raised blood sugar: studies in newly detected hyperglycaemics. II. Urinary albumin excretion, blood pressure and their relation to blood sugar levels. Guy's Hosp Rep 118: 247-254

9. Viberti GC, Pickup JC, Jarrett RJ, Keen H (1979) Effect of control of blood glucose on urinary excretion of albumin and $\beta_{2}$-microglobulin in insulin-dependent diabetes. $N$ Engl J Med 300: 638-641

10. Viberti GC, Pickup JC, Bilous RW, Keen H, Mackintosh D (1981) Correction of exercise-induced micro-albuminuria in insulin-dependent diabetics after 3 weeks of subcutaneous insulin infusion. Diabetes 30: 818-823

11. Parving H-H, Noer I, Deckert T, Evrin P-E, Nielsen SL, Lyngsoe J, Mogensen CE, Rorth M, Svendsen PA, Trap-Jensen J, Lassen NA (1976) The effect of metabolic regulation on microvascular permeability to small and large molecules in short-term juvenile diabetics. Diabetologia 12: 161-166

12. Mogensen CE (1976) Renal function changes in diabetes. Diabetes $25: 872-879$

13. Mauer SM, Brown DM, Matas AJ, Steffes MW (1978) Effects of pancreatic islet transplantation on the increased urinary albumin 
excretion rates in intact and uninephrectomised rats with diabetes mellitus. Diabetes 27:959-964

14. Rasch R (1980) Prevention of diabetic glomerulopathy in streptozotocin diabetic rats by insulin treatment. Diabetologia 18: 413-416

15. Mauer SM, Steffes MW, Brown DM (1981) The kidney in diabetes. Am J Med 70: 603-612

16. Pirart J (1977) Diabète et complications dégénératives. Présentation d'une étude prospective portant sur 4,400 cas observés entre 1947 et 1973 (three parts). Diabete Metab 3: 97-107; 173-82; $245-256$

17. Guthrow CE, Morris MA, Day JF, Thorp S, Boynes JW (1979) Enhanced non-enzymatic glucosylation of human serum albumin in diabetes mellitus. Proc Natl Acad Sci 76: 4258-4261

18. Cohen MP, Urdamivia E, Surma M, Ciborowski CJ (1981) Nonenzymatic glycosylation of basement membranes. In vitro studies. Diabetes $30: 367-371$

19. Hostetter TH, Troy JL, Brenner BM (1981) Glomerular hemodynamics in experimental diabetes mellitus. Kidney Int 19: 410-415

20. Deckert T, Parving H-H, Andersen AR, Sandahl-Christiansen J, Oxenbell B, Svendsen PA, Telmer S, Christy M, Lauritzen T, Thomsen OF, Kreiner S, Andersen JR, Binder C, Nerup J (1982) Diabetic nephropathy. A clinical and morphometric study. In: Eschwege E (ed) Advances in diabetes epidemiology. Elsevier Biomedical Press, Amsterdam, pp 235-243

21. Parving H-H, Jensen HA, Mogensen CE, Evrin P-E (1974) Increased urinary albumin excretion rate in benign essential hypertension. Lancet 1: 1190-1192

22. Steffes MW, Brown DM, Mauer SM (1978) Diabetic glomerulopathy following unilateral nephrectomy in the rat. Diabetes 27 : $35-41$
23. Mauer SM, Steffes MW, Azar S, Sandberg SK, Brown DM (1978) The effects of Goldblatt hypertension on development of the glomerular lesions of diabetes mellitus in the rat. Diabetes 27 : 738-744

24. Brod J, Bahlmann J, Cachovan M, Pretschuer P (1983) Development of hypertension in renal disease. Clin Sci 64: 141-152

25. Pedersen EB, Mogensen CE (1976) Effect of antihypertensive treatment on urinary albumin excretion, glomerular filtration rate, and renal plasma flow in patients with essential hypertension. Scand J Clin Lab Invest 36: 231-237

26. Gordon T, Kannel WB (1972) Predisposition to atherosclerosis in the head, heart and legs. The Framingham Study. JAMA 221: 661-666

27. Parving H-H, Smidt UM, Friisberg B, Bonnevie-Nielsen V, Andersen AR (1981) A prospective study of glomerular filtration rate and arterial blood pressure in insulin-dependent diabetics with diabetic nephropathy. Diabetologia 20: 457-461

28. World Health Organisation (1962) Arterial hypertension and ischaemic heart disease. Preventive aspects. Report of an expert committee. Technical Report Series No.231, Geneva.

Received: 5 September 1983

and in revised form: 19 March 1984

Dr. M. Wiseman

Unit for Metabolic Medicine

Guy's Hospital Medical School

London, SE1 9RT, UK 